\title{
COMPETENCY-BASED EVALUATION FOR CREATIVE AND EXPERIMENTAL IMMERSION CHALLENGE
}

\author{
Rubén VÁZQUEZ, Fermín RAMÍREZ, Marisol ÁLVAREZ TOSTADO, Ana Sofía ZARATE, \\ and Alejandro ACUÑA \\ Tecnológico de Monterrey, Mexico
}

\begin{abstract}
"Suffocating" is the name given to the transmedia interactive installation, product of the challenge that 28 students achieved in five weeks as part of the Immersion and Creative Experimentation Block (This document refers to Block as a multidisciplinary project with a design challenge and a scheme consisting of modules, which are evaluated by competencies). Based on the text "Redondillas" by Sor Juana Inés de la Cruz (1689), students seek to make the harassment that women experience on the street daily visible. This Block is part of the new Tec 21 educational model, as an educational innovation strategy of the Entrance to Creative Studies at Tecnológico de Monterrey (first year of undergraduate studies in creative and related disciplines). The Block is composed of four modules that cover Fundamentals of Design, Creative Writing, Audio visual Production and Volumetric Construction, with students profiles of architecture, design, digital art, communication, journalism, music production, Hispanic letters and educational innovation, they work in a collaborative and multidisciplinary way with their different profiles for five weeks, in which they develop transversal and disciplinary skills, which are co-evaluated among peers and evaluated in a collegial way by the professors of each module that makes up the Block, using Canvas and E-Lumen, as key tools in the process of qualifying and feedback to students.
\end{abstract}

Keywords: Competencies-based learning, challenge-based learning, Bloque Tec21, educational innovation, higher education

\section{INTRODUCTION}

Tecnológico de Monterrey is the most prestigious private multi-campus university in Mexico and the third best university in Latin America (according to the QS Ranking 2020). For 6 years, the Tecnológico de Monterrey began to implement the TEC21 Model, an innovative educational model adapted to the new times and the characteristics of the young people of the $21^{\text {st }}$ Century. In August 2019, a new academic structure called Block was implemented for the first time, which consists of a multidisciplinary project consisting of modules and the resolution of a design challenge, which are evaluated by competencies and with a duration of 5,10 or 15 weeks. The present work is based on the Block called Creative Immersion and Experimentation, from the Creative Studies entrance of the San Luis Potosí campus. In this 5-week block, 28 freshmen from different disciplines such as Architecture, Design, Digital Art, Journalism, Communication and Educational Innovation participated. This document will present an overview of the course methodology and evaluation method, as well as the main lessons learned.

\section{METHODOLOGY}

The block consists of a challenge and four content modules necessary to meet the challenge. It begins with an evaluation diagnosis of the principles and foundations of expressive languages (literary, sound, visual and spatial), followed by three content modules that provide inputs for the execution of the challenge. Each of the modules corresponds to a stage in the process of acquiring the declared skills for this training unit. 


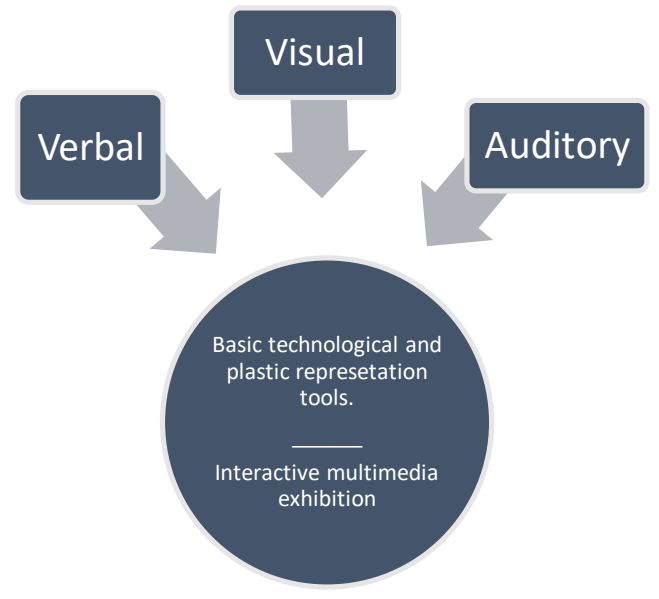

Figure 1. Elements and principles of languages

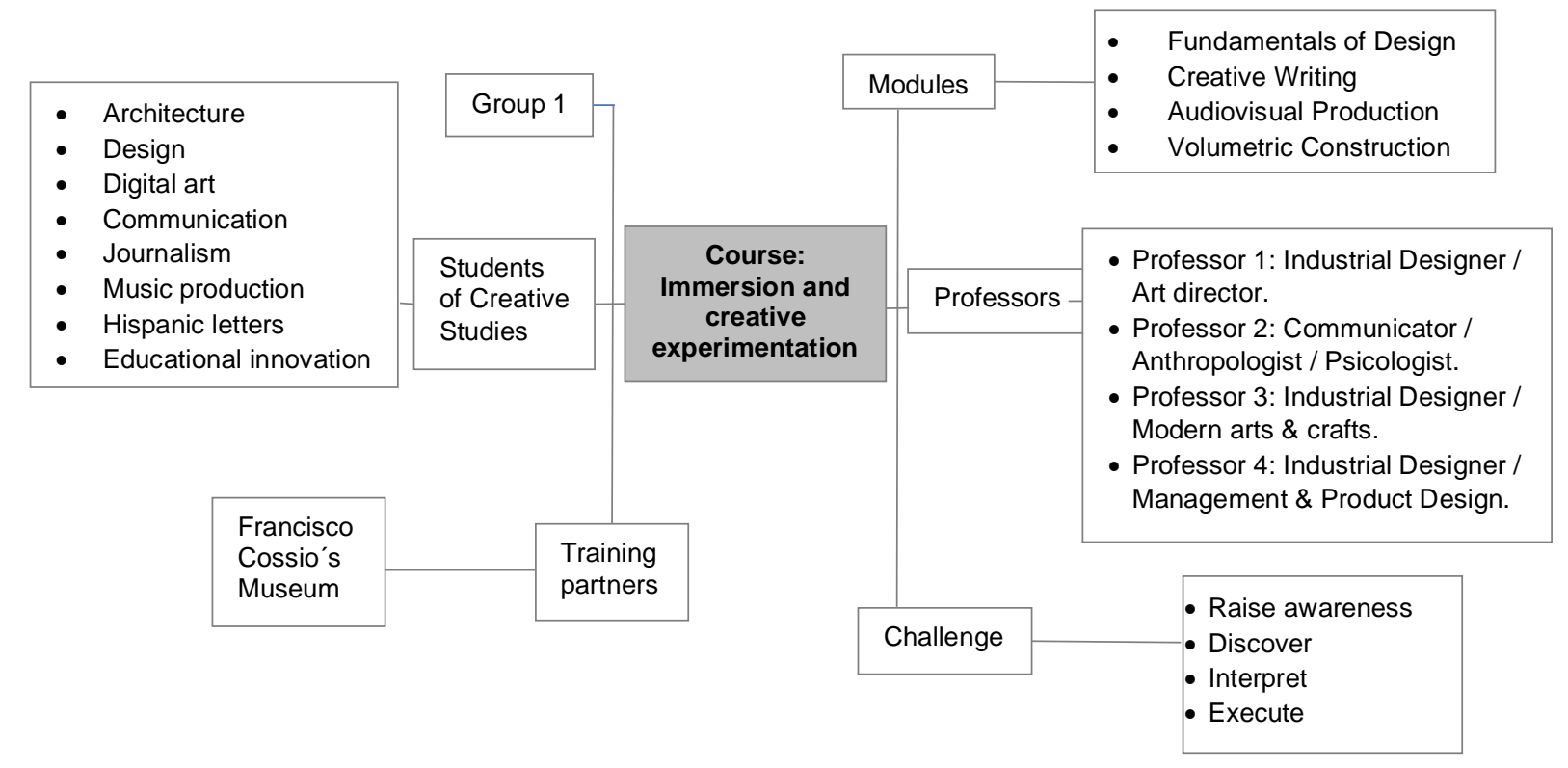

Figure 2. Course Structure

\subsection{Modules}

\subsubsection{Fundamentals of Design}

Teacher 1. Different stages were applied so that the student became familiar with the Fundamentals of Design and raise awareness of the importance of these when wanting to develop a concept from scratch. In the first stage, students need to know the different design foundations and through examples seen in class, it was appreciated how they could be applied in different areas of design, architecture and communication. In the second stage the students themselves began to develop their compositions using the concepts learned. After that, students could analyse the proposals of other classmates and perceive the intention of the concept they wanted to convey. Finally, they met to elaborate a project under a Brief and limitations, as well as a delivery date in which all the students had to participate in a team and apply different skills for a common objective.

\subsubsection{Creative Writing}

Teacher 2. In the sessions of the block, through theoretical and reflexive presentations in addition to various dynamics in which the students participated, an approach was made to the creative fact, to the verbal descriptions where the fundamentals of communication were touched, for what and for whom it communicates, in addition to analysing the usefulness of verbal language as a communication tool for a creative proposal; elements for the poetic composition and analysis of a literary canonical work. In this 
block we chose Sister Juana Inés de la Cruz's poem "Argues for inconsequence the taste and censorship of men, which in women accuse what they cause", which the generated reflection mainly on roles and moral that has perpetuated the female figure as subordinate to the male.

\subsubsection{Audio visual Production}

Teacher 3. The students delivered exercises related to the challenge to be developed and to the tools learned in class from each programme: Adobe Illustrator (They delivered a poster based on the challenge presentation), Photoshop (They delivered edited images within the programme based on the artistic expression of the challenge) and After Effects (The students previously recorded sounds and voiceovers to create an animated composition that included visual, sound and artistic aspects. The recording of voiceovers was later used by the students to create an immersive experience within the challenge).

\subsubsection{Volumetric Construction}

Teacher 4. This module provides the basis for the handling of laminated materials and foams, their commercial presentations, properties and characteristics, as well as their use for the construction of models and prototypes. Two scale models 1:5 and an interactive transmedia installation scale 1:1 were made. Two additional awareness activities took place: one about synaesthesia (We play and share food and called it "Culinary Experience") and the other about human rights and gender violence (supported by the Municipal Coordination of Human Rights of San Luis Potosí).

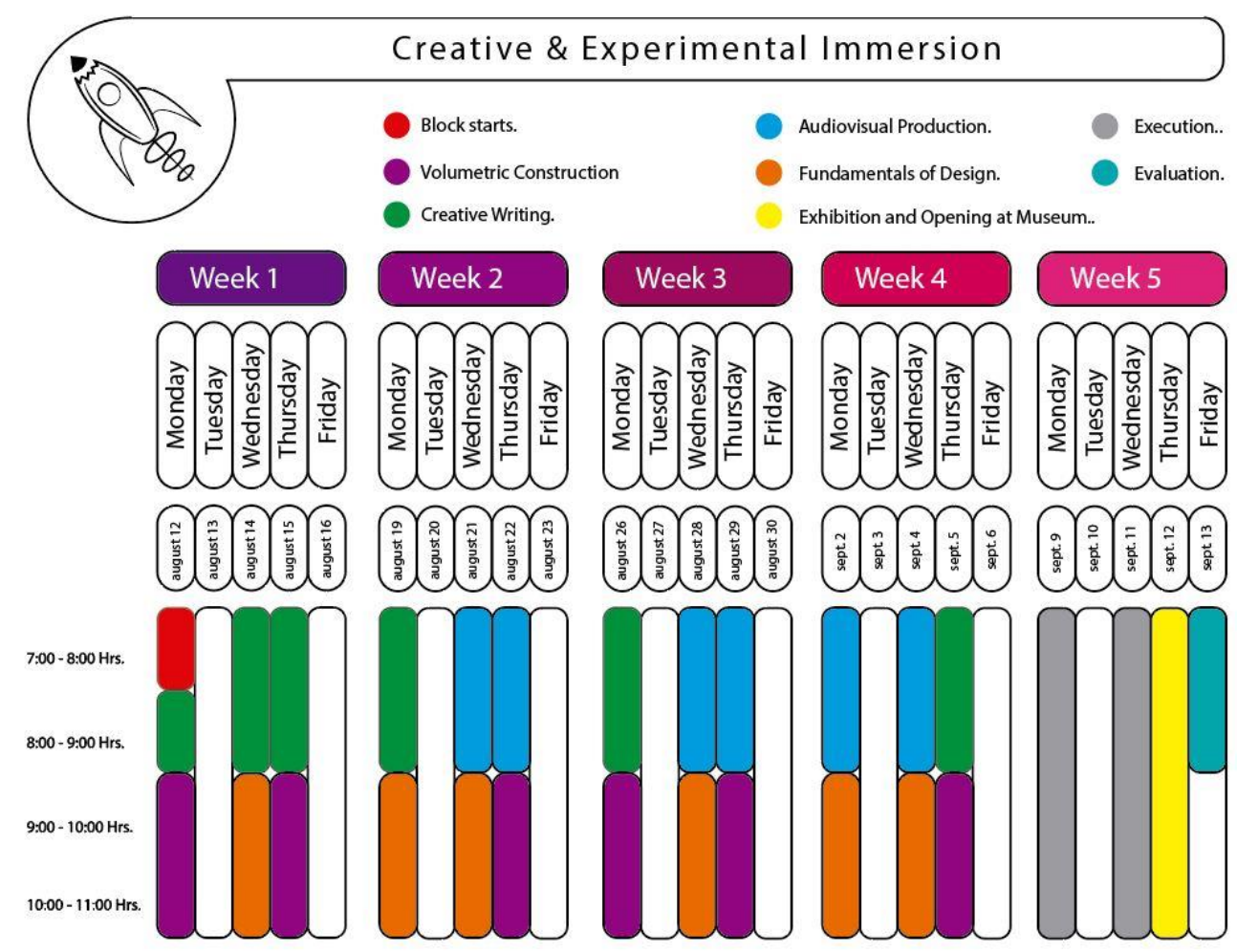

Figure 3. Block Calendar with Modules per week

\subsection{Competencies}

This section shows the competencies and sub competencies to be developed in this block, as well as the levels of mastery that must be achieved in each one. They are called according to the "SESCO" key corresponding to the "Creative Studies" area.

1. SESCO100. Design of creative proposals: Design creative proposals based on the analysis of the social, cultural and arts context

2. SESCO200. Creation of narrative and experimental content: Create relevant narratives using languages, formats and specialized technologies appropriate to different cultural fields.

3. SESCO300. Significant Representation: Represents design solutions based on meaningful intent using visualization and materialization techniques.

4. SESCO400. Technologies in Art: Integrates technologies experimentally in the design and production of creative projects 
5. SEGO300. Social Intelligence: It generates effective collaboration and negotiation environments in multicultural contexts with respect and appreciation for the diversity of people, knowledge and cultures.

\subsection{Context}

Gender-based violence was considered as a theme to address, through the reinterpretation of the poem "Redondillas" by Sor Juana Inés de la Cruz. Currently there is a crisis of feminicides in México. In the last 5 years, these have increased 137\% [5]. One in ten victims of femicide is a minor. Despite the high figures, some organizations, such as the National Citizen Observatory of Feminicide, believe that the number could be much higher, since some homicides are not properly classified as femicide. Today, Mexico is a country where, on average, ten women are killed a day [3].

\subsection{Challenge}

The student's group were formed by 18 women and nine men. Their challenge was to design and produce an interactive transmedia installation based on a canonical artistic object, such as an explicit reinterpretation offered to a specific public or community. The installation was required to be in a space suitable for contemplation and interaction. The composition needed to comply with the principles of visual syntax, and its manufacture must guarantee its usability. The installation was accompanied by a report that included a justification of the proposal (format, a specific material, a particular composition, etc.) was chosen, the scope (what is intended to be expressed) and how it relates to the selected work. Each of the modules corresponds to a stage in the process of acquiring the declared skills for this training unit.

Stage 1. Awareness: In this first stage students will recognize their knowledge and skills for creative production through several interpretation exercises that will serve as a diagnostic to identify their strengths and weak areas, working both individually and collectively.

Stage 2. Discovery: At this stage they knew the variety of tools offered by each of the expressive languages, as well as their specialized terminology, to use it properly in the analysis and production of artifacts.

Stage 3. Interpretation: At this stage they are immersed in the process of conceptualizing a collective transmedia work based on explicit interpretation of a canonical text, which they had to present as an artistic proposal to their classmates.

Stage 4. Execution: In this stage the group worked collectively in the execution of the project chosen in the previous stage. This process required a lot of teamwork and organization.

The structure of the challenge can be related to the Double Diamond model, developed by the British Design Council in 2005; since, as can be seen, its structure is similar, having four stages in which the problem is discovered, the information obtained is defined, different or proposed are developed and the one that best solves the problem is delivered.

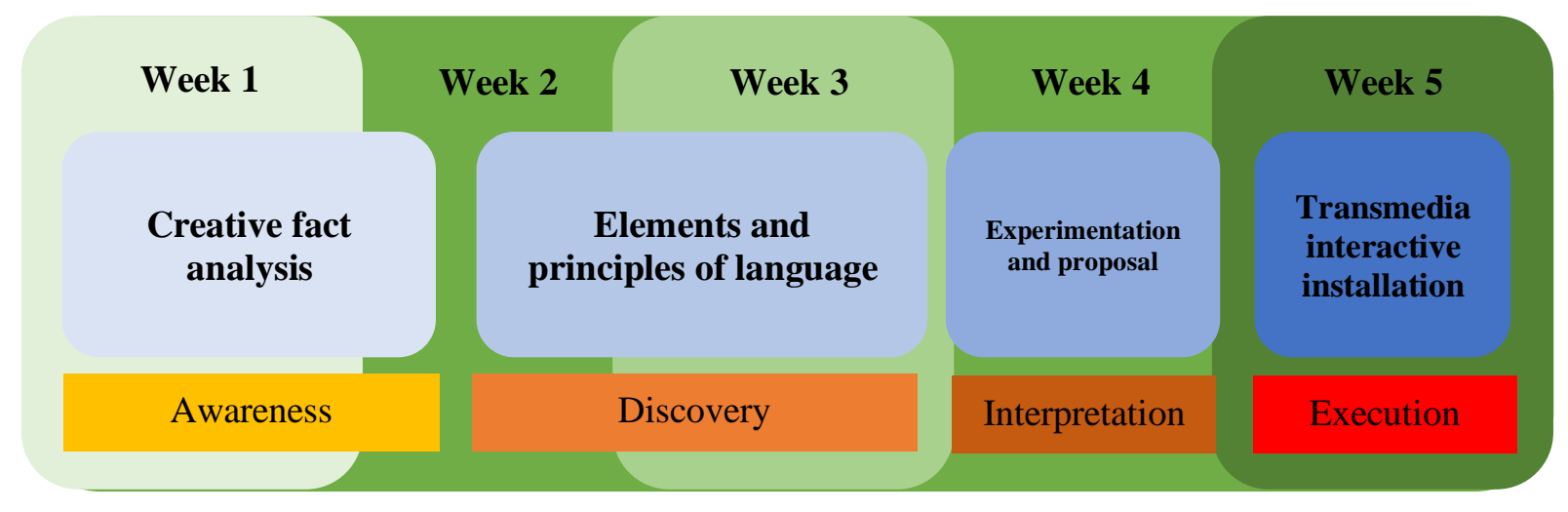

Figure 4. Stages of immersion and creative experimentation

\section{EVALUATION}

\subsection{Peer evaluation}

A cross-scheme analysis was performed between the mid-term and final coefficients where the first served as a basis to understand the processes of each student during the five weeks of the block. Each 
of the co-evaluation questions corresponded to the competence SEGO301A: Respect diversity as an enriching element of personal and professional work with foundation in human rights, in different knowledge and different cultures. Recognize the diversity as an enriching element of your personal and professional work, based on fundamental human rights, the concept of gender, and understand the advantages of diversity. It can integrate this knowledge into teamwork, manifesting the openness, interest and willingness towards diversity. She or He resorts frequently to the help of teacher to solve the conflicts resulting from diversity.

Where Respect was measured with the following questions:

1. Were they kind and respectful to his classmates?

2. Were they punctual and committed in the elaboration of the project?

Teamwork was measured with:

1. Were they committed, interested and helped in the elaboration of the project?

2. Were they available to attend the project work sessions?

3. Do they shared ideas and contributed solutions, hoping that the project had the best quality?

4. Do they collaborate with the search for materials, construction and costs?

Problem solving:

1. Do they often use the teacher's help to solve the conflicts resulting from the diversity?

As a group 52\% felt very satisfied with the result, while $42 \%$ felt satisfied; $8 \%$ almost satisfied and not satisfied. In the comments they mentioned as a communication improvement area mainly, as well as improve cooperation, participation, coordination, teamwork and time organization.

\subsection{Tools}

The co-assessment was sent to the students through Google Forms, to later send the data to the competency assessment matrixes. These were evaluated using the E-Lumen platform. The rest of the activities and follow-up of the challenge took place through the Canvas Instructure platform. The students also elaborated a time-lapse video, to show all the stages of the process; it was very helpful for the professors while evaluating individual work and participation, the video served as an extra evidence of each student's work.

\section{RESULTS}

In the first two weeks, each of the six teams worked on an individual proposal for transmedia installation. By week 4, the best proposal that had a good concept and technical feasibility had been chosen. Thus, suffocating was born. The main idea was to generate a corridor with MDF (Medium Density Fibre) panels mounted on steel PTR structures (Rectangular Tubular Profile). The panels were perforated to support rolled polyethylene foam tubes to generate "phalluses" that simulate hand rubbing through an alley, as a symbolism of harassment suffered by women on the streets. In addition to this, speakers were installed inside the panels with an MP3 player, which emitted sounds of "cat calling" and whistles, characteristic of harassment. In the centre of the installation there was a mirror with the phrase "Foolish people who accuse others for no reason" alluding to Sor Juana's poem and re-signifying it. The passage through the hall represented that you enter being a person, and you leave being another, at least in terms of gender perspective. With this method, the level of commitment of the students, as well as the quality of the deliverables were remarkable and of very good quality. With peer assessment you can easily identify people with a higher participation level and take actions to break the apathy and indifference that may exist in teamwork. The collegiate evaluation made this a transparent and easy-to-understand process for students, as well as an accompaniment among professors that has as a result a consensual and much more solid evaluation. It became a memorable first semester experience, as it does not remain a project within the school. The possibility of disappointing the training partner is not an option (the museum in this case), quality standards are established in the processes, finishes and exhibition, which sets a precedent and the basis for future projects. In the end, students were reminded that they should not forget what they were already able to do. 


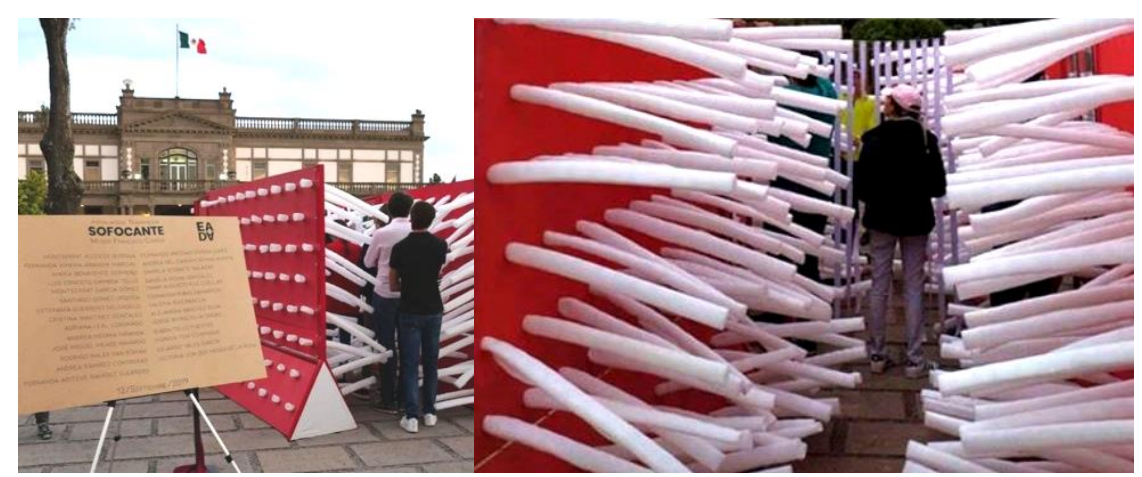

Figure 4. "Suffocating" installation, in the Francisco Cossío Museum

\section{FUTURE WORK}

It is considered that the challenge, being related to a gender issue and seeking to make violence visible and raise awareness, was reinforced in large part by the attitude and mentality of the students, who were passionate about the subject. It marked a before and after as a generation, being the first in San Luis Potosí to address the issue and be the first block of its experience as part of the Tec21 model. For future instalments of this block, the competent authorities in Human Rights and Gender Violence could be invited, with the intention of reaching more people with the message and linking it with the initiatives that the authorities have on these issues to see their real impact.

Based on the work on this project, some students sought to form a student group called AIRE, which (in Spanish) corresponds to the acronym for Association for Integrity, Respect and Equity, on issues of sexual diversity and inclusion. From now on, the Creative and Experimental Immersion Block can be a space to address issues of gender, feminism and LGBTQI+ community, in collaboration with AIRE and other campus associations such as Girl Up and He for She.

\section{AKNOWLEDGEMENT}

The authors would like to acknowledge the financial and the technical support of Writing Lab, and Tecnologico de Monterrey, Mexico, in the production of this work.

\section{REFERENCES}

[1] Ching, F. D. K. Arquitectura. Forma, Espacio y Orden (13th ed.). 2002, México, México: Gustavo Gili.

[2] HALLGRIMSSON, B. DISEÑO DE PRODUCTO: MAQUETAS Y PROTOTIPOS. 2012, Barcelona, España: Promopress.

[3] Observatorio Ciudadano Nacional del Feminicidio. INFORME IMPLEMENTACIÓN DEL TIPO PENAL DE FEMINICIDIO EN MÉXICO: DESAFÍOS PARA ACREDITAR LAS RAZONES DE GÉNERO 2014-2017. 2018, Retrieved from https://92eab0f5-8dd4-485d-a54fb06fa499694d.filesusr.com/ugd/ba8440_66cc5ce03ac34b7da8670c37037aae9c.pdf

[4] P O S T E R IT Y - Arte Transmedia, definiciones y ejemplos recientes. Available: https://www.posterity.store/blog/arte-transmedia-definiciones-ejemplos-recientes [Accessed 2020, 09 March], (2018), 11 November.

[5] Rodríguez, I. C. Data Sources on Violence Against Women in Mexico: What We Have Learned, Further Difficulties and Challenges (Vol. 8, Núm. 1, enero-abril 2017). 2017, Retrieved from https://www.inegi.org.mx/rde/rde_20/doctos/rde_20_art1.pdf

[6] Scott, R. G. Fundamentos del diseño (13th ed.). 1990, México, México: Limusa.

[7] SOLÉ BLANCH, J. El cambio educativo ante la innovación tecnológica, la pedagogía de las competencias y el discurso de la educación emocional. Una mirada crítica. Teoría de la Educación. Revista Interuniversitaria, 2020, 32(1(en-jun)), 101. https://doi.org/10.14201/teri.20945

[8] Wong, W., Thevenet, H. A., and Miralles, E. R. Fundamentos del diseño (17th ed.). 2011, Barcelona, España: Gustavo Gili.

[9] La Hacienda Studio. Modelo de Diseño de Doble Diamante. (2019, octubre 14). Recuperado 19 de mayo de 2020, de https://medium.com/la-hacienda-studio/modelo-de-dise\%C3\%B1o-deldoble-diamante-2625d9b0b3af 